Received: June 29, 2017

\title{
Research on the Innovative Development Mode of Quality Education of College Students Based on the Perspective of Human Resource Management
}

\author{
Wenwu $\mathrm{Li}^{1}$ \\ Inner Mongolia University of Finance and Economics
}

\begin{abstract}
The innovative development of quality education for college students is an important goal of the cultivation in higher education and plays an important role in the development of the country. This paper takes the perspective of human resource management as the basic idea, focuses on the innovative development of the quality education of college students and discusses the educational mode of the cultivation of college students' innovation quality. The research results show that in the knowledge-based economy environment, it is necessary to cultivate and develop the innovation ability of college students in quality education and seek the connection between the career development counselling and human resource management among individual college students. From the perspective of human resource management, the dual cultivation mode should be adopted to strengthen the self-cognition and career planning of college students. This paper uses the analytic hierarchy process (AHP) and support vector machine (SVM) to evaluate the innovative development of the quality education of college students and establishes a dynamic evaluation system for the quality education of college students. This paper proposes a complete solution for the innovative development of the quality education of college students.
\end{abstract}

\section{Keywords}

College Students • Innovative Development of Quality Education • Higher Education • Human Resource Management

\footnotetext{
${ }^{1}$ Correspondence to: Wenwu $\mathrm{Li}(\mathrm{PhD})$, School of business administration Inner Mongolia University of finance and economics, Inner Mongolia, hohhot 010070, China. Email: lww116@126.com

Citation: Li, W.W. (2018). Research on the Innovative Development Mode of Quality Education of College Students Based on the Perspective of Human Resource Management. Educational Sciences: Theory \& Practice, 18(5), 2447-2454. http://dx.doi.org/10.12738/estp.2018.5.144
} 
With the development of the national economy and science and technology education, the education plays a direct promoting role in this progress and there is an increasing demand for high-quality composite talents with pioneering and innovative ability (İsmail \& Funda, 2015). The traditional education mode suppresses the creative ability of students to a certain extent and solidifies the thinking mode of students (Nishigaki, Ezoe, Kitajima \& Hata, 2017). In China, a large number of research scholars has carried out researches on the innovation ability of college students, which promotes the theoretical development to a certain extent and becomes an important tool to guide practice (Teklehaimanot \& Teklehaimanot, 2013). Different cultivation programs can cultivate the innovative thinking and idea of college students and the cultivation of innovative ability calls for the combination of acceptance learning and discovery learning. Also, the divergent thinking and non-logical thinking need to be used to analyze, explore and solve problems, cultivate the innovative thinking college of students and implement innovative ability training (Adirim, Meade \& Mistry, 2016).

Human resource is characterized by initiative, potentiality, synchronism and timeness. College students are special human resources for the country with high learning ability and learning ability is the fundamental driving force for college students to achieve innovation and creation (Marin, 2012). College students with innovative ability generally have creative thinking, reasonable knowledge structure, strong practical ability and good psychological quality (Atak \& Erturgut, 2010). The innovation of college students requires a wide range of interests and hobbies, pioneering thinking pattern, keen information capture capability, strong communication and cooperation awareness, and healthy and stable psychological quality (Yan \& Zhu, 2012). This paper takes the perspective of human resource management as the basic idea, focuses on the innovative development of the quality education of college students and discusses the educational mode for the cultivation of college students' innovative quality.

\section{Innovative Cultivation of College Students' Quality Education from the Perspective of Human Resource Management}

Knowledge economy and global innovation have become the highlights in global economic development and in the final analysis, the global competition is the competition of talent and technology (Caiyun, 2012). In the current era, improving the innovative ability and level of college students can lay the foundation for building an innovative country; improving the employability and competitiveness of college students can adapt to the needs of market economy development; the combination of the comprehensive development and the personality development of students can lay a foundation for their lifelong development (Heinrich, Geis \& Schulz, 2016, Wiley, 2013). Compared with developed countries such as the United States, the innovation cultivation mode of college students in China has defects in the aspects of targeting and positioning, including: the criticism of "craving for greatness and success" and the lack of innovative impetus from students, which is also affected by the market economy system in China.

In recent years, the autonomy of college students has been greatly improved and they have more opportunities to participate in social practice projects, which has greatly improved their practical ability. Moreover, the de-administration in colleges and universities has obtained certain achievements and the school 
has gradually formed the philosophy of "professor management, independent recruitment". From the perspective of human resource management, it is necessary to adopt the target incentive, interest incentive, reward incentive and competition incentive in the innovation of college students' quality education. The teaching concept of in colleges and universities should abandon the old education concept and establish innovative educational concept. Moreover, it is necessary to constantly cultivate high-quality teachers and build the cultivation mode of college students.

\section{Construction of the Cultivation Mode of Innovative Quality}

\section{Career Planning, Employability and Entrepreneurship College Students}

The quality education innovation of college students is closely related to ability cultivation, exploration of innovation potential and self-cognition. Figure 1 is a composition diagram of the cultivation of the career planning awareness of college students. The cultivation of the whole career planning awareness of college students includes goal guidance, cognitive guidance and career guidance. The cognitive guidance includes career planning and life development, university study and career development, professional social cognition and self-exploration and cognition. The detailed career planning can enhance the competitiveness of college students promote the rational allocation of human resources, thus providing a good occupational environment for college students. Quality education innovation is a long-term process, which not just focus on the logical analysis and manipulative ability of college students during schooldays. In fact, most of the quality education innovation ability is manifested in or after the employment. The development of quality education innovation ability is closely related the occupation.

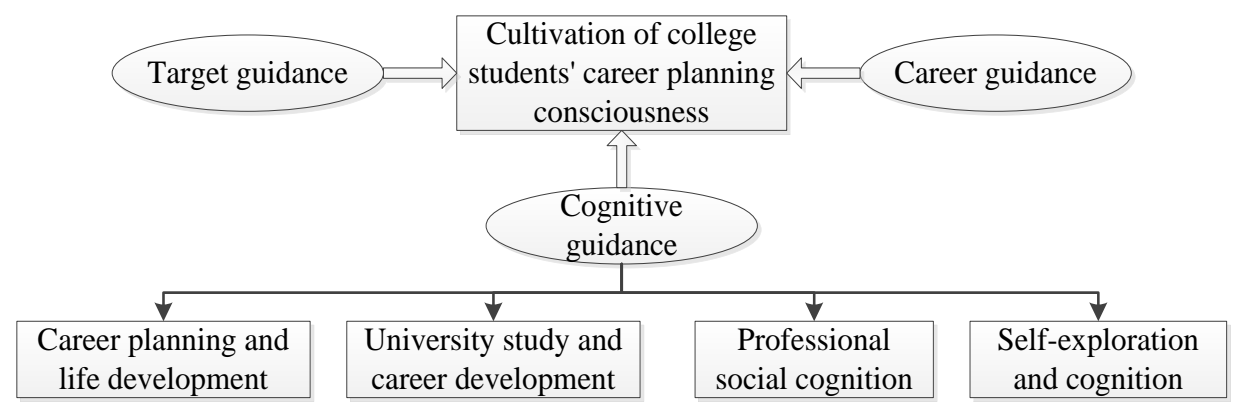

Figure 1. College students' career planning awareness training composition.

\section{Innovation Resource Cultivation Plan}

At present, the proportion of theoretical and practical courses arranged in colleges and universities is unbalanced and there is a lack of integrated scientificity between the practical and theoretical courses, including unscientific time arrangement, course order and method integration. The innovative development of the quality education for college students requires a constructivist teaching model. Teachers play the guiding and leading role and the school serves as a student practice platform so as to greatly promote students' initiative. Figure 2 is 
a diversified extracurricular practice mode. Classroom teaching can be used as a platform of case, inspiration and problem-based education for college students. Extracurricular practice, as a platform for college students to participate in social practice, can be used as a second classroom. The practical ability includes on-site practice, comprehensive and design experiments, simulating the scene and various scenes, and implementing experiments independently. Figure 3 shows the basic procedure of the activity teaching mode. The overall implementation draws on the constructivist theory and implements the three-step teaching reform mode, which finally stimulates the interest, develops the innovative ability, highlights the individuality and activates the thinking of college students.

In addition to the change of the cultivation mode and college education of colleges and universities, the selfmanagement and self-education ability of college students are also crucial, which calls for their self-cognition, self-regulation, self-construction and self-transcendence. The individual behavior of students needs to realize self-management relying on student organizations and student associations. College students should transform knowledge education and behavioral education into self-requirement and internalize the education. Only in this way can the purpose of education be achieved through the organic integration process of education and selfeducation.

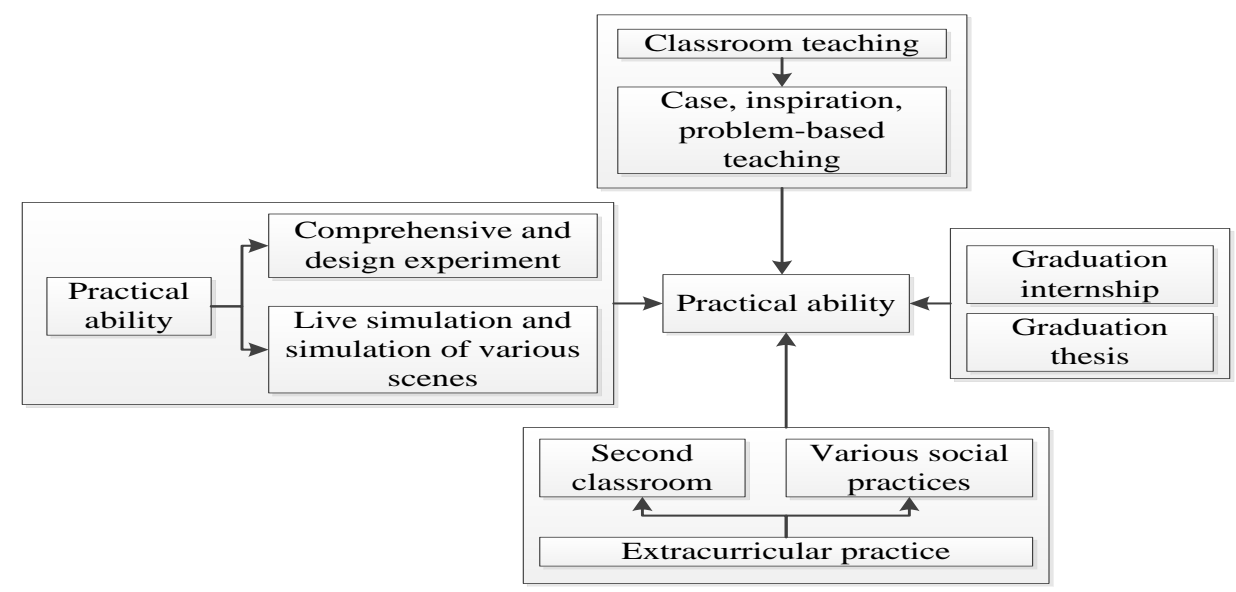

Figure 2. Diversified extracurricular practice pattern.

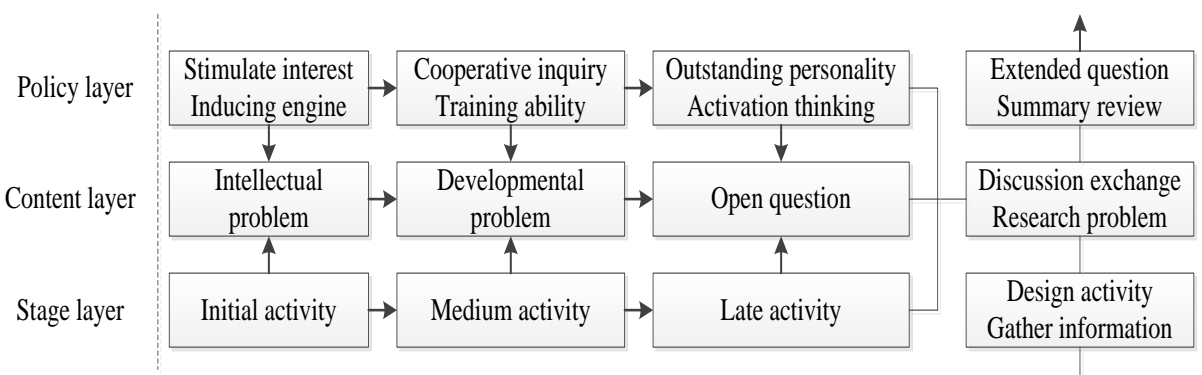

Figure 3. Basic procedure of the activity class teaching mode. 


\section{Evaluation System and Empirical Application of the Innovative Development of Quality Education}

\section{Research on Evaluation System}

The commonly used methods for the evaluation system the innovative development of quality education are analytic hierarchy process and fuzzy evaluation method. The analytic hierarchy process and support vector machine are used in this paper for the analysis. The analytic hierarchy process is the dynamic evaluation system of the comprehensive quality and innovation ability of college students and through the consistency test and normalization of the learning performance, dormitory performance, campus cultural and sports activities, social practice public welfare action, academic activities and achievements in scientific research of college students. The consistency test criteria of the analytic hierarchy process are shown in Table 1.

The support vector machine is a new type of data mining technology with strong generalization ability, which can realize the situation that the final result is determined by a minority of support vectors. Figure 4 is a schematic diagram of the support vector machine classifier. There are many hyperplanes that can separate the data, but only one hyperplane can achieve the maximum separation. Parallel hyperplanes can be represented by equation set, as shown in equation 1 and 2 :

$$
w \cdot x-b=-1
$$

w. $x-b=1$

In this equation: $\mathrm{w}$ is a vector perpendicular to the hyperplane; $\mathrm{x}$ is the point on the hyperplane; and $\mathrm{b}$ is the displacement interval.

Table 1

Consistency Test Standard for Analytic Hierarchy Process

\begin{tabular}{lllllllllll}
\hline Order & 1 & 2 & 3 & 4 & 5 & 6 & 7 & 8 & 9 & 10 \\
\hline RI & 0 & 0 & 0.59 & 0.91 & 1.13 & 1.25 & 1.33 & 1.42 & 1.46 & 1.50 \\
\hline
\end{tabular}

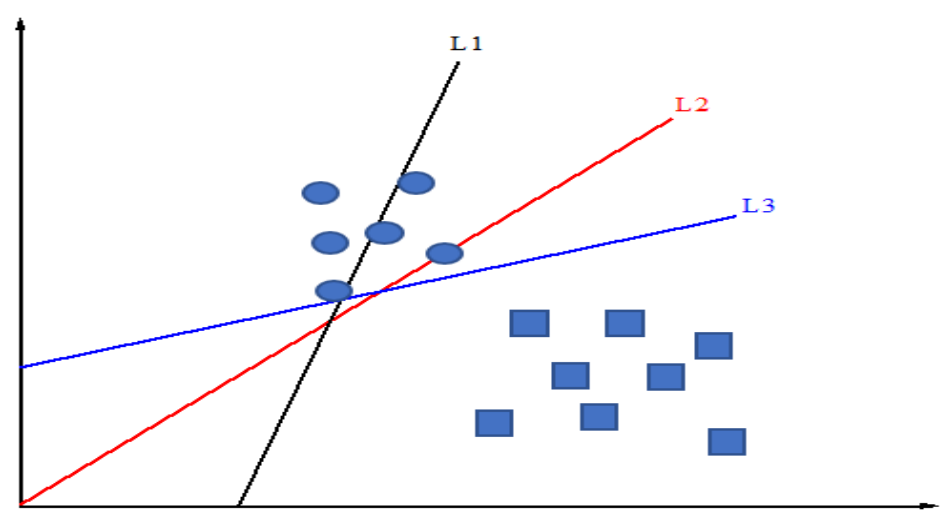

Figure 4. Schematic diagram of support vector machine classifier. 


\section{Theoretical Deepening and Expansion}

The construction of the development counselling system of college students can achieve the goal of the comprehensive development of college students and deepen the quality education. The innovative development of the quality education of college students is the main task to promote the all-round development of college students. "Comprehensive, coordinated and sustainable" development is the goal of the development counselling system of college students; comprehensive, whole-process, and large-coverage counselling is the content in the development counselling system. Figure 5 is a practical operation diagram of the development counselling system of college students. The development counselling system of college students includes three parts: development counselling center, growth classroom and practice innovation training program, which provides the counselling on the career, study, personality and life of college students. Also, the research and innovation training programs of college students are conducted and the practice bases are established, which enriches the social practice and campus cultural activities.

From the perspective of human resource management, it is necessary to adopt a dual cultivation mode to strengthen the self-cognition and career planning of college students. Higher education is an important way to improve the learning and thinking ability of college students and the results of the quality education innovation of college students are determined by the market value. The current work is to combine the individual value of students, the value of school cultivation and market value to cultivate the college Students with the human resource development vision. The dual cultivation development mode should use the concept of human resource development to improve the ability, quality and taste of college students; to improve the self-assessment and self-positioning ability of college students; to build a professional teacher team of career planning education; to arrange systematic career planning curriculum; to strengthen the tie with employers.

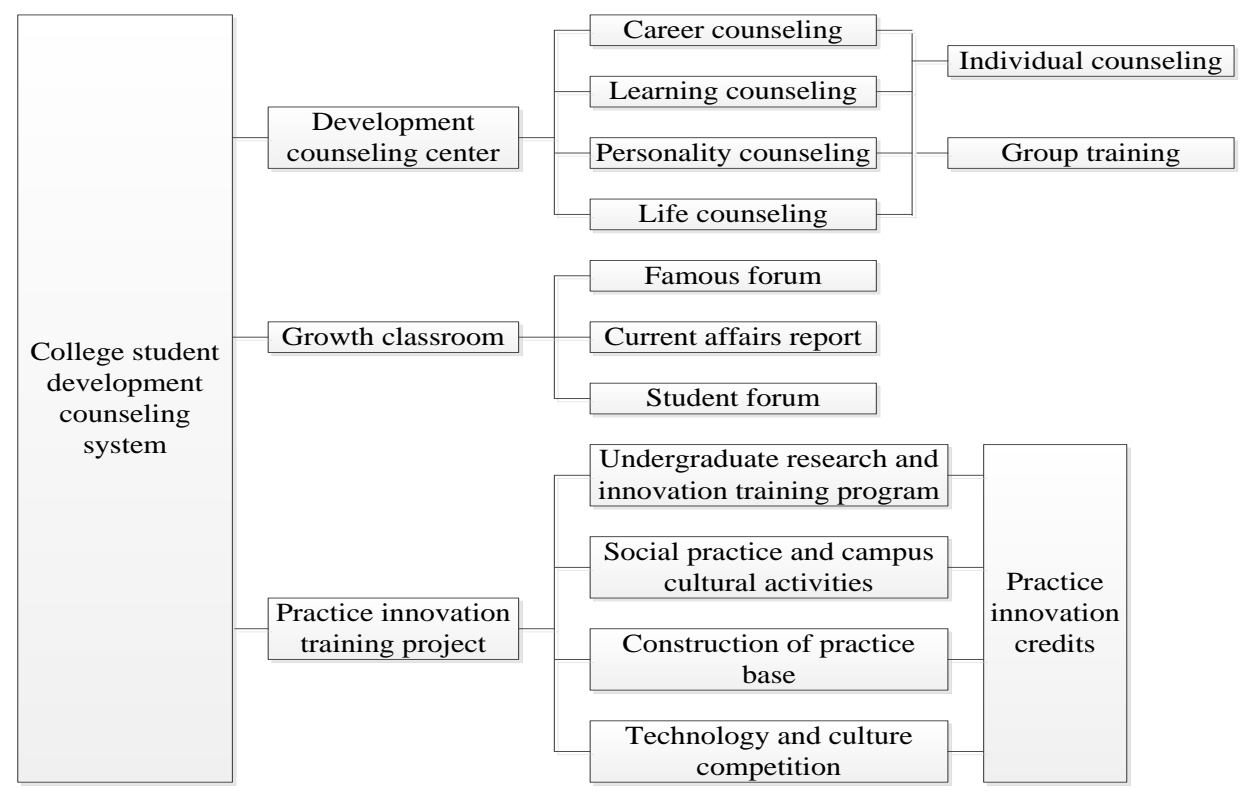

Figure 5. Practice operation chart of college students' development counselling system. 


\section{Development of Dynamic Evaluation System}

The structure of the dynamic evaluation system should have good comprehensiveness, ease of use, reliability and applicability. The main function of the system is to realize the dynamic analysis of the quality education of college students and the scientization and informationization of the evaluation. Also, it should have comprehensiveness, qualitative and quantitative combination, guiding and universal comparability principles. The development includes the establishment of a scientific and sound evaluation system, the primary analysis application module of the quality education of college students, the data acquisition design and advanced analysis function; the functional modules developed include analysis and early warning module, management module, data acquisition module and performance collection module. Figure 6 shows the diagram of system query analysis and warning. The whole function module includes analysis and early warning module, management module, data acquisition module and performance collection module.

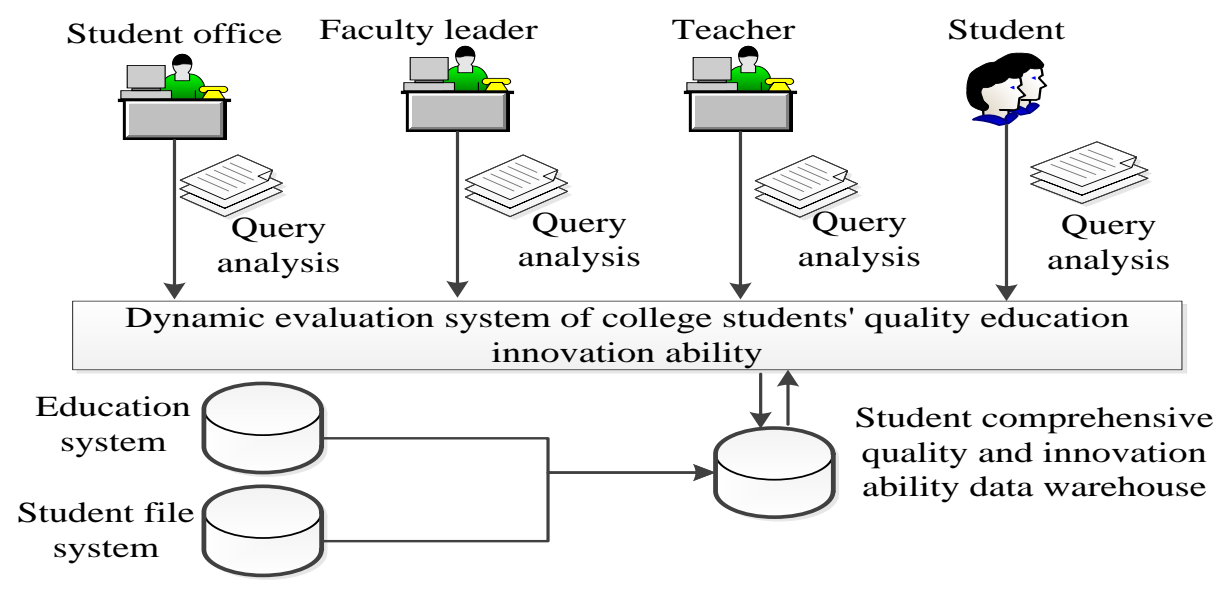

Figure 6. System query analysis and warning prompt map.

\section{Conclusion}

This paper takes the perspective of human resource management as the basic idea, focuses on the innovative development of the quality education of college students and discusses the educational mode of the cultivation of college student's' innovative quality. The specific conclusions are as follows:

(1) Quality education innovation is a long-term process, which not just focus on the logical analysis and manipulative ability of college students during schooldays. In fact, most of the quality education innovation ability is manifested in or after the employment. The development of quality education innovation ability is closely related the occupation. 
(2) From the perspective of human resource management, the dual cultivation mode should be adopted in strengthening the self-cognition and career planning of college students. Specially, the concept of human resource development should be used to improve the ability, quality and taste of college students and develop a comprehensive, whole-process, and large-coverage development counselling system.

\section{References}

Adirim, T., Meade, K., \& Mistry, K. (2016). A new era in quality measurement: the development and application of quality measures. Pediatrics, 139(1), e20163442. http://dx.doi. org/10.1542/peds.2016-3442

Atak, M., \& Erturgut, R. (2010). Importance of educated human resources in the information age and view of information society organizations on human. Procedia - Social and Behavioral Sciences, 2(2), 1452-1456. http://dx.doi. org/10.1016/j.sbspro.2010.03.217

Caiyun, S. (2012). Research on training mode of high-level innovative talents in computer science in colleges. Procedia Engineering, 29, 2749-2753. http://dx.doi. org/10.1016/j.proeng.2012.01.384

Heinrich, L., Geis, I., \& Schulz, W. H. (2016). The impact of product failure on innovation diffusion: the example of the cargo bike as alternative vehicle for urban transport. Transportation Research Procedia, 19, 269-271. http://dx.doi. org/10.1016/j.trpro.2016.12.086

İsmail, B., \& Funda, G. (2015). Analysis of innovation-based human resources for sustainable development. Procedia - social and behavioral sciences, 195, 1348-1354. http://dx.doi. org/10.1016/j.sbspro.2015.06.321

Marin, S. M. (2012). Change and innovation in the educational policies and strategies for human resources development. Procedia - Social and Behavioral Sciences, 47(1), 1662-1667. http://dx.doi. org/10.1016/j.sbspro.2012.06.880

Nishigaki, F., Ezoe, S., Kitajima, H., \& Hata, K. (2017). Human resource development contributes to the creation of outstanding regenerative medicine products. Regenerative Therapy, 7(C), 17-23. http://dx.doi. org/10.1016/j.reth.2017.06.002

Teklehaimanot, H. D., \& Teklehaimanot, A. (2013). Human resource development for a community-based health extension program: A case study from Ethiopia. Human Resources for Health, 11(1), 39. http://dx.doi. org/10.1186/1478-4491-11-39

Wiley. (2013). Perspectives on adult education, human resource development, and the emergence of workforce development. New horizons in Adult Education \& Human Resource Development, 26(1), 13-21. http://dx.doi. org/10.1002/nha3.20049

Yan, Y. Y. \& Zhu, Q. Y. (2012). Research on the innovation of training mode for professional personnel of computer. IERI Procedia, 2, 161-166. http://dx.doi. org/10.1016/j.ieri.2012.06.068 